\title{
Seasonal Temperature Dependence of Availability of Under-Water Visible Optical Communications through Egypt Nile River Water
}

Seif eldin A. Zaghloul ( $\nabla$ eng_seif.eldin@yahoo.com )

Zagazig University Faculty of Engineering

\section{Bedir Yousif}

Kafrelsheikh University Faculty of Engineering

Walid S. El-Deeb

Zagazig University Faculty of Engineering

\section{Research Article}

Keywords: Underwater visible optical communications, ray trace model, optical channel loss model, Nile river water, pure water, link availability, water attenuation

Posted Date: August 11th, 2021

DOI: https://doi.org/10.21203/rs.3.rs-662023/v1

License: (9) This work is licensed under a Creative Commons Attribution 4.0 International License. Read Full License 


\title{
Seasonal Temperature Dependence of Availability of Under-Water Visible Optical Communications through Egypt Nile River Water
}

\author{
Seif Eldin A. Zaghloul ${ }^{1}$, BedirYousif ${ }^{2}$ and Walid S.El-Deeb ${ }^{3}$ \\ ${ }^{1,3}$ College of Engineering, Zagazig university, ${ }^{2}$ College of Engineering, Kafr Elshikh University
}

\begin{abstract}
Underwater visible optical communications become very important for their high velocity and more data rate. But the optical is suffering from the high water attenuation. For optical communication. Pure water is the best of the ten water types with wavelengths $\lambda=455$ and $486 \mathrm{~mm}$. The Nile river water is a pure water without salinity (fresh water). The temperature of the water is daily changes and so the performance of optical communication underwater becomes temperature-dependent.
\end{abstract}

A simplified expression very good accuracy of Egypt Nile water to determine the water refractive index, water dispersion, water attenuation, received optical power, and SNR as direct temperature dependence is done.

The optical channel loss model is used to determine the received optical power and the ray trace model is used to define optical radiation pattern. The equation of optical received power by ray trace is the same as that by using the optical channel loss model except for the transmitter gain of them are different.

For $\lambda=486 \mathrm{~nm}$ with water temperature varying from $4^{\circ} \mathrm{C}$ to $30^{\circ} \mathrm{C}$, the corresponding refractive index decreases from 1.3399 to 1.3379 (so, the optical velocity under fresh water increases from $2.239 * 10^{8} \mathrm{~m} / \mathrm{s}$ to $2.2423 * 10^{8} \mathrm{~m} / \mathrm{s}$ ), dispersion decreases from 0.6492 to $0.6459(\mathrm{ps} / \mathrm{m} \mathrm{nm})$, attenuation factor decreases from $0.0378 \mathrm{~m}^{-1}$ to $0.0345 \mathrm{~m}^{-}$

${ }^{1}$ and so the required transmitted optical power due to attenuation for $800 \mathrm{~m}$ long shrinks to $7.4 \%$.

The Effect of temperature becomes more evident with more link distance.

The required transmitted power to achieve the required SNR increases with the more data rate. To overcome the unavailability of the link due to water temperature, the transmitted power must be controlled by the daily water temperature.

In this study, the temperature dependence of the performance of the optical link and a simulation proposed example design is done.

Keywords: Underwater visible optical communications, ray trace model, optical channel loss model, Nile river water, pure water, link availability, water attenuation.

\section{Introduction}

The underwater visible optical communications become very more important to the degree there are multi researches to develop this technology[1]-[10]. Until now, the aims of researches are optical communication underwater links with large distance and high data rate (bit rate)[11]. Underwater communications are required in many applications such as the transfer of messages and speech transmission between submarine ships[8]. The main challenge of this technology is the high water attenuation (absorption and scattering) of optical waves[3]. Also the varying seasonal water temperature (approximately from $5^{\circ} \mathrm{C}$ to above $30^{\circ} \mathrm{C}$ ).

The blue/green band of 430 to $550 \mathrm{~nm}$ gives a lower attenuation of the visible spectrum[3], [9] and the leader wavelengths are $\lambda=455$ and $486 \mathrm{~nm}$ (with pure water[9], [12].

Water attenuation $\left(\alpha \mathrm{m}^{-1}\right)$ depends upon the type of water. Pure water is one of the tenth water types[13]. Water is classified according to the attenuation coefficient $\left(\alpha_{\mathrm{FW}}\right)[1]$. The Nile River water is fresh water (pure water without salinity and perhaps there is very little particulate concentration). Pure water has an absorption greater than scattering [14] and in the pure sea water $\left(\mathrm{C}_{\mathrm{c}}=0.005\right.$ and $\alpha=0.043 \mathrm{~m}^{-1}[10]$, [15]). The value of $\alpha_{\mathrm{FW}}$ increases with the temperature at wavelength $\lambda=455 \mathrm{~nm}$ while it decreases with temperature at wavelength $\lambda=486 \mathrm{~nm}$. And so, with $\lambda=455 \mathrm{~nm}$, as the water temperature increases, the allowed link distance, the received power and the SNR are lowered but vice versa with $\lambda=486 \mathrm{~nm}$.

The speed of the optical wave in water is approximately 0.75 of the speed of light in vacuum (where water refractive index around 1.34) and it increases with increasing both temperature and wavelength. The dispersion of water decreases slowly with temperature and so the allowed data rate increases with temperature. 
The Beer's law [1], [15] is used with a link distance less than the diffusion length [9], [15]. But the modified Beer-Lambert law is used with a link distance greater than the diffusion length.[3], [9]

With a narrower transmitter half-power angle $\left(\varphi_{1 / 2}\right)$ the power density becomes better, also, the underwater channel could be regarded as a non-dispersive medium [3]

Single LED is generally modeled by means of a generalized Lambertian radiation pattern[11].

The receiver cross-section area is small (around $400 \mathrm{~cm}^{2}$ ) and so the distributions of both the received power density and SNR are approximately uniform inside the received area.

The link availability of the required transmitted power is the smaller value of the required transmitted power due to attenuation and due to SNR.

The pass optical loss model [16], [17] gives the received optical power and the SNR therefore the availability of the optical link and the ray trace model [9], [11], [18], [19] is used to study the power pattern through the propagation distance.

\section{In this study}

The optical wave propagation under-water is studied by using both the ray trace model [9], [18], [19] and the optical channel model[1], [20]. The equation of received power of the ray trace model is converted into the format of the optical channel losses model. The difference between the two models is the transmitter gain. The ray trace model gives a good description of the optical transmission. .

A simplified expression with very well accuracy for fresh water (Egypt Nile River water) to define the water refractive index $\left(n_{\mathrm{FWT}}\right)$, water dispersion $\left(\mathrm{D}_{\mathrm{FWT}}\right)$, water attenuation $\left(\alpha_{\mathrm{FWT}}\right)$, received optical power $\left(\mathrm{P}_{\mathrm{r}}\right)$ and SNR as a direct temperature dependence are done for temperature changes from $5^{\circ} \mathrm{C}$ to $40^{\circ} \mathrm{C}$ (seasonal changes in temperature) with leader wavelengths $(\lambda=455$ and $486 \mathrm{~nm})$ and without particulate concentration (i.e. $\mathrm{C}_{\mathrm{c}}=0 \mathrm{mg} / \mathrm{m}^{3}$ ). A proposed simulation design of underwater optical communication links is done.

\section{Mathematical Analysis \\ II.1 Refractive Index, dispersion and Attenuation of fresh water}

\section{II.1.1Refractive index $\left(\mathrm{n}_{\mathrm{FW}}\right)$ and dispersion $\left(\mathrm{D}_{\mathrm{FW}}\right)$ of fresh water}

i-The refractive index of fresh water( $\left.n_{\mathrm{FW}}\right)$ as a function of wavelength $(\lambda \mathrm{nm})$ and temperature $\left(\mathrm{T}^{\circ} \mathrm{C}\right)$ is defined as [21] ;

Where,

$$
n_{F W}=n_{F W 1} n_{\text {air }}
$$

$$
\begin{aligned}
& n_{F W 1}=a_{0}+a_{1} T^{2}+\frac{\left(a_{2}+a_{3} T\right)}{\lambda}+\frac{a_{4}}{\lambda^{2}}+\frac{a_{5}}{\lambda^{3}} \\
& n_{\text {air }}=1+10^{-8}\left\{\frac{k_{1} \lambda^{2}}{\left(\lambda^{2}-k_{2}\right)}+\frac{k_{3} \lambda^{2}}{\left(\lambda^{2}-k_{4}\right)}\right\}
\end{aligned}
$$

Constants $\mathrm{a}_{1}-\mathrm{a}_{5}$ and $\mathrm{k}_{1}-\mathrm{k}_{4}$ are stated in Appendix A.1.1.

As the temperature and wavelength increase, the refractive index decreases as shown in Fig.1 and as explained in [13]. Therefore the optical wave velocity increases with water temperature.

ii-The dispersion of unguided wave is considered as the material dispersion $\left(\mathrm{D}_{\mathrm{FW}}\right)$ [22] ;

$$
\mathrm{D}_{\mathrm{FW}}=\frac{-1000}{3} \frac{\mathrm{d}^{2} \mathrm{n}_{\mathrm{NW}}}{\lambda^{2}} \quad[\mathrm{ps} /(\mathrm{m} \mathrm{nm})] \quad \text { with } \lambda \text { in } \mathrm{nm}
$$

From Fig.2, as the temperature increases, the dispersion decreases slowly. While as the wavelength increases, the dispersion decreases. Therefore the data rate $(\mathrm{Br})$ increases slowly with temperature.

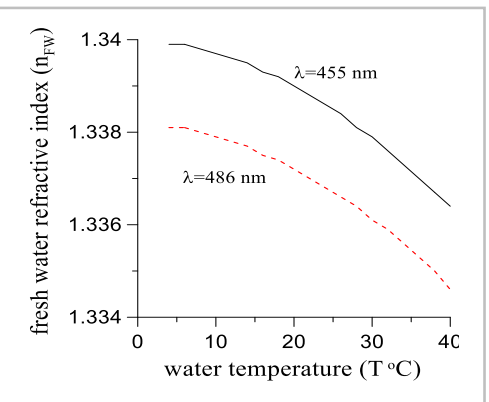

Fig.1 Refractive index ( $\mathrm{n}_{\mathrm{FW}}$ ) versus $\mathrm{T}$

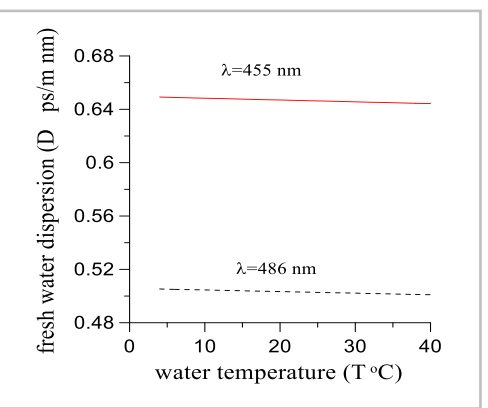

Fig.2 Dispersion $\left(\mathrm{D}_{\mathrm{FW}}\right)$ versus $\mathrm{T}$ 


\section{II.1.2Attenuation of fresh water}

Attenuation of fresh water is the summation of the absorption $\left(a_{F W T} m^{-1}\right)$ and scattering $\left(b_{F W T} m^{-1}\right)$

I-Water absorption as a function of both wavelength and temperature ( $\left.b_{\mathrm{FWT}}\right)$;

The values of the absorption coefficient of fresh water at temperature $\mathrm{T}=20^{\circ} \mathrm{C},\left(\mathrm{a}_{\mathrm{FW}}{ }_{20}\right)$ are stated in[13], [23]-[25]. A formula between the $\mathrm{a}_{\mathrm{FW}} 20$ and the operating wavelength $\lambda$ is derived from these data by using the least square fitting curve technique at $\lambda=455$ to $515 \mathrm{~nm}$ as;

$$
a_{F W \lambda T 20}=d_{5}+d_{6} \lambda+d_{7} \lambda^{2}+d_{8} \lambda^{3}+d_{9} \lambda^{4}+d_{10} \lambda^{5}+d_{11} \lambda^{6}+d_{12} \lambda^{7} \quad(\text { for } 455 \leq \lambda<515)
$$

Constants $\mathrm{d}_{0}-\mathrm{d}_{16}$ i are stated in Appendix A.1.2

The absorption coefficient at a different temperature than $20^{\circ} \mathrm{C}$ becomes [21]

$$
a_{F W \lambda T}=a_{F W 20}+(T-20) F_{T}
$$

Where, $\mathrm{F}_{\mathrm{T}}$ is the single temperature-specific coefficient of pure water absorption. $\mathrm{F}_{\mathrm{T}}$ is calculated from [21] where, $\mathrm{F}_{\mathrm{T}}=0.00025$ (with $\lambda=455$ ) and -0.0001 (with $\lambda=486 \mathrm{~nm}$ ). Note, the absorption coefficient $\alpha_{\mathrm{FW} \lambda \mathrm{T}}$ changed by -0.004 to $+0.007 / /^{\circ} \mathrm{C}[21]$ according to the operating wavelength.

An additional absorption due to dissolved particulates $\left(a_{\text {part }}\right)$ with concentration $\left(\mathrm{C}_{\mathrm{c}} \mathrm{mg} / \mathrm{m}^{3}\right)$ and the total absorption becomes [3], [13]

$$
a_{F W \lambda T P}=\left(a_{F W \lambda T 20}+0.06 g_{c} C_{c}^{0.65}\right)\{1+0.2 \exp [-0.014(\lambda-440)]\}
$$

Where, $\mathrm{g}_{\mathrm{c}}$ is the non-dimensional chlorophyll-specific absorption coefficient and it is a function of wavelength. The parameter, $\mathrm{g}_{\mathrm{c}}$ is derived from data [13], [21]by using the best fitting technique as;

$$
g_{c}=d_{17}+d_{18} \lambda+d_{19} \lambda^{2}+d_{20} \lambda^{3}
$$

The values of $d_{17}-d_{20}$ are stated in Appendix A.1.3.

Another definition of the value of the additional absorption $\left(\mathrm{a}_{\mathrm{part}}\right)$ due to concentration particulate are the summation of the absorption due to Chlorophyll $\left(\mathrm{a}_{\mathrm{cp}}\right)$,the absorption due to Fuluic acid $\left(\mathrm{a}_{\mathrm{fp}}\right)$ and the absorption due to Humic acid (a $\mathrm{a}_{\mathrm{hp}}$ ) [1], [14], [19], [26], [27]as;

$$
a_{F W \lambda T P}=a_{F W \lambda T}+a_{c p}+a_{f p}+a_{h p}
$$

Where; $\quad a_{c p}=0.06 g_{c} C_{c}^{0.65}$

$$
\begin{aligned}
& a_{f p}=62.6007 C_{c} \exp (0.12327-0.0189 \lambda) \\
& a_{h p}=3.6402 C_{c} \exp (0.12343-0.0105 \lambda)
\end{aligned}
$$

\section{Ii-Fresh water scattering}

The volume scattering of the pure fresh water $\left(\mathrm{B}_{\mathrm{FW} \lambda \mathrm{T}}\right)$ is defined as the summation of the scattering due to the density fluctuations $\left(\mathrm{B}_{\mathrm{d}}\right)$ and the scattering due to the concentration fluctuation $\left(\mathrm{B}_{\mathrm{c}}\right)$ [21], [28]. But for fresh water the value of $B_{c}=0$ (where there isn't salinity) and so $B_{F W \lambda T}$ becomes;

$$
B_{F W \lambda T}=B_{d}
$$

The dependence of $B_{d}$ on the temperature and wavelength is [21], [28]

$B_{d}\left(m^{-1}\right)=10^{32} \frac{\pi^{2}}{2 \lambda^{4}}\left\{\left(n_{F W}^{2}-1\right)\left[1+0.6666\left(n_{F W}^{2}+2\right)\left(n_{F W}^{2}-1\right)^{2} \frac{1}{9 n_{F W}^{2}}\right]\right\}\left\{K_{B} T_{K} f(\delta)\right\} \frac{1}{\beta_{T}}$

Where,

$\beta_{\mathrm{T}}$ is the isothermal compressibility; $\quad \beta_{T}=\left(c_{0}+c_{1} T+c_{2} T^{2}+c_{3} T^{3}+c_{4} T^{4}\right)$

$\mathrm{f}(\delta)$ is the Cabbbanes factor of water; $\quad \mathrm{f}(\delta)=(6+6 \delta) /(6-7 \delta), \delta=0.04$ [21], [28].

$\lambda$ is the wavelength $(\mathrm{nm}), \quad \mathrm{T}$ is the temperature $\left(\mathrm{T}^{\circ} \mathrm{C}\right), \mathrm{T}_{\mathrm{K}}$ is the temperature in ${ }^{\circ} \mathrm{K}$ and $\mathrm{K}_{\mathrm{B}}$ is the Boltzmann constant $\left(1.38^{*} 10^{-23} \mathrm{~J} /{ }^{\circ} \mathrm{K}\right)$. Constants $\mathrm{c}_{1}$ to $\mathrm{c}_{4}$ are stated in Appendix A.1.4.

If there is a particulates with concentration $\left(\mathrm{C}_{\mathrm{c}} \mathrm{mg} / \mathrm{m}^{3}\right)$, an additional scattering $\left(\mathrm{B}_{\text {part }}\right)$ must be taken in account [1], [19], [26], [27], [29];

$$
\mathrm{B}_{\text {part }}=0.02 \mathrm{C}_{\mathrm{c}}\left(\frac{400}{\lambda}\right)^{1.7} \exp \left(0.11631 \mathrm{C}_{\mathrm{c}}\right)+0.26 \mathrm{C}_{\mathrm{c}}\left(\frac{400}{\lambda}\right)^{0.3} \exp \left(0.03092 \mathrm{C}_{\mathrm{c}}\right)
$$

The total volume scattering becomes;

$$
B_{F W \lambda T P}=B_{d}+B_{\text {part }}
$$

The freshwater scattering coefficient $\left(\mathrm{b} \quad \mathrm{m}^{-1}\right)$ is defined as [13]

$$
b_{F W \lambda T}\left(m^{-1}\right)=16.07 B_{N W}
$$

Note 1; Eq. 10 is verified with $\left(\lambda=270\right.$ to $1100 \mathrm{~nm}, \mathrm{~T}=0$ to $30^{\circ} \mathrm{C}$ )

Note 2; the scattering of fresh water at $20^{\circ} \mathrm{C}$ is

Without particles[12]; $\quad b_{F W \lambda T 20}=0.005826(400 / \lambda)^{4.322}$

While with particulate ( $\left.\mathrm{b}_{\mathrm{FW} \lambda \mathrm{T} 20 \mathrm{P}}\right)$ is[3], [13], $b_{F W \lambda T 20 P}=0.30 C_{c}^{0.62}(550 / \lambda)$ 
Note 3 ; if $b$ is calculated at $\lambda_{\mathrm{o}}$, the value of $\mathrm{b}$ at wavelength $\lambda$ becomes [13]

$$
b(\lambda)=b\left(\lambda_{o}\right)\left(\lambda_{o} / \lambda\right)^{4.32}
$$

Note 4; the mean free path distance before scattering is the reciprocal of water absorption

$$
\left(\mathrm{L}_{\text {no scattering }}=1 / \mathrm{a}_{\mathrm{FW} \lambda \mathrm{TP}} \mathrm{m}\right)[19], \text { [26], [29] }
$$

Note 5; Backscattering can be neglected with short distance [13]

iii-Attenuation coefficient $\left(\alpha_{\mathrm{FW} \lambda \mathrm{T}} \mathrm{m}^{-1}\right)$ is the sum of scattering and absorption [1]-[3], [15]

$$
\alpha_{F W \lambda T}=a_{F W \lambda T}+b_{F W \lambda T}
$$

The attenuation coefficient function of wavelength [30] increases with temperature (for $\lambda=455 \mathrm{~nm}$ ) while it decreases with temperature (for $\lambda=486 \mathrm{~nm}$ ). Also, it increases with concentration particulate $\left(\mathrm{C}_{\mathrm{c}} \mathrm{mg} / \mathrm{m}^{3}\right)$. The attenuation coefficient with $\lambda=486$ is the smallest value. As shown in Fig.3,

Figure 3 indicates that, for fresh water at $\mathrm{T}=20{ }^{\circ} \mathrm{C}, \alpha_{\mathrm{FW}}(\lambda=486 \mathrm{~nm})<\alpha_{\mathrm{FW}}(\lambda=455 \mathrm{~nm})$ as explained in[12], [13]. The wavelength $\lambda=486 \mathrm{~nm}$ is the best for under fresh water optical communications because attenuation is the smallest and the variation of attenuation due to temperature is less. As the temperature increases, the values of $\alpha_{\mathrm{FW}}(\lambda=455 \mathrm{~nm})$ increase while $\alpha_{\mathrm{FW}}(\lambda=486)$ decreases.

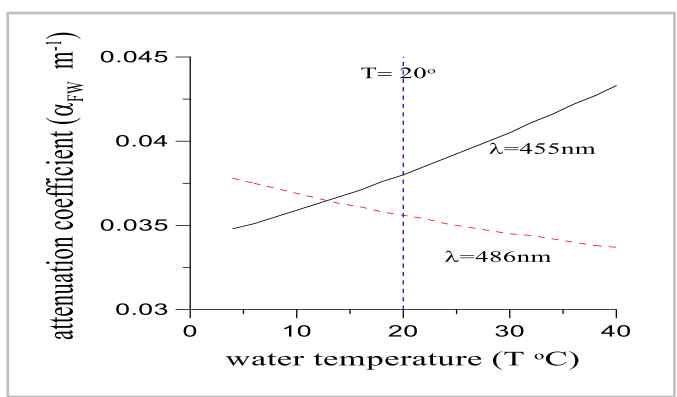

Fig.3 Attenuation coefficient $\left(\alpha_{\mathrm{FWT}} \mathrm{m}^{-1}\right)$ for fresh water without particulate concentration $\left(\mathrm{C}_{\mathrm{c}}=0\right)$

\section{IV- Water losses}

If the propagation is a line of sight (LOS) and with link distance (L) less than the diffusion distance ( $\mathrm{L}_{\text {diffusion, }} \mathrm{L}_{\text {diffusion }}=15 / \alpha$ [9]), the water losses are calculated by the famous Beer's law $\left\{\right.$ loss $=\mathrm{e}^{-\alpha \mathrm{L}}$, where, $\mathrm{L}(\mathrm{m})$ and $\alpha\left(\mathrm{m}^{-1}\right)$ [1], [9], [15]\}. Otherwise the modified Beer's law is used[9].

Note: LOS means a component of the light propagation is referred to as the portion of the light radiated by the transmitter that arrives directly within the field of view (FOV) of the receiver[11].

The diffusion length $\left(\mathrm{L}_{\text {diffusion}}\right)$ decreases with temperature (with $\lambda=455$ ) but $\mathrm{L}_{\text {diffusion }}$ increases with temperature $\left(\lambda=486 \mathrm{~nm}\right.$ ). The value of $\mathrm{L}_{\text {diffusion }}=429.41 \mathrm{~m}$ (for $\lambda=455 \mathrm{~nm}, \mathrm{~T}=5^{\circ} \mathrm{C}$ ), 370.23 (for $\lambda=455 \mathrm{~nm}$ , $\mathrm{T}=305^{\circ} \mathrm{C}$ ), $398.77 \mathrm{~m}$ (for $\lambda=486 \mathrm{~nm}, \mathrm{~T}=5^{\circ} \mathrm{C}$ ), and $424.63 \mathrm{~m}$ (for $\lambda=486 \mathrm{~nm}, \mathrm{~T}=30^{\circ} \mathrm{C}$ ).

Note, $\mathrm{L}_{\text {diffusion }}$ at $5^{\circ} \mathrm{C}$ for $\lambda=455 \mathrm{~nm}$ greater than that at $\lambda=486 \mathrm{~nm}$ and vice versa for $\mathrm{T}=30^{\circ} \mathrm{C}$, where from Fig.3, with $\mathrm{T}<12^{\circ} \mathrm{C}, \alpha_{\mathrm{FW}}$ at $\lambda=486>\alpha_{\mathrm{FW}}$ at $\lambda=455$.

From reference[9], we noticed that the propagation loss factor independent of the half-power angle of the transmitter $\left(\varphi_{1 / 2}\right)$ where the value of propagation loss factor with $\varphi_{1 / 2}=5^{0}$ equally with that $\varphi_{1 / 2}=10^{\circ}$ as explained in Appendix B.

v- Approximate temperature dependence of refractive index $\left(\mathrm{n}_{\mathrm{FWT}}\right)$, dispersion $\left(\mathrm{D}_{\mathrm{FWT}}\right)$ and attenuation coefficient $\left(\alpha_{\mathrm{FWT}}\right)$ are defined by using fitting curve technique with very good agreement ( T varying from 0 to $40{ }^{\circ} \mathrm{C}$ ) as;

-Refractive index (Eq.1) at specific wavelength for T varying from 0 to $40{ }^{\circ} \mathrm{C}$, becomes;

$$
n_{\text {FWT } \text { apr }}=q_{1}-q_{2} T-q_{3} T^{2}
$$

With percentage error of Eq.17.a, $\mathrm{Rn}_{\mathrm{FWT}} \%=0.00069$ and 0.00011 with $\lambda=455$ and $486 \mathrm{~nm}$, respectively. - Absolute dispersion (Eq.2) as a function of $\mathrm{T}$ at the mentioned four wavelengths is derived as;

$$
\operatorname{abs}\left(D_{F W T \text { apr }}\right)=q_{4}-q_{5} T
$$

With percentage error of Eq.17.b $\mathrm{RD}_{\mathrm{FWT}} \%=0.00020$ and 0.00071 for $\lambda=455$ and 486 , respectively. - Attenuation coefficient ( $\left.\alpha_{\mathrm{FWT}} \mathrm{Eq} .16\right)$ at the mentioned wavelengths without particulate concentration $\left(\mathrm{C}_{\mathrm{c}}=0 \mathrm{mg} / \mathrm{m}^{3}\right)$ and with particulate $\left(\mathrm{C}_{\mathrm{c}}=0.005 \mathrm{mg} / \mathrm{m}^{3}\right)$ is;

$$
\alpha_{F W T}\left(m^{-1}\right)=q_{6}+q_{7} T+q_{8} T^{2}
$$


With percentage error of Eq.17.c, $R \alpha_{\mathrm{FW}}=0.274(\mathrm{~T}=5)$ to $0.041(\mathrm{~T}=40), 0.135(\mathrm{~T}=5)$ to $0.037(\mathrm{~T}=40)$, for $\lambda=455$ and $486 \mathrm{~nm}$, respectively.

Where, constants $\mathrm{q}_{1}-\mathrm{q}_{8}$ are stated in Appendix A.

The Percentage error $=100$ (exact - approximate value)/exact value

\section{II.2 Optical Beam}

\section{II.2.1 Optical Channel losses model}

The received optical power (power budget) [1], [16], [17]

$$
P_{R}=P_{t} \quad G_{t} G_{r}\left(\frac{\lambda}{4 \pi R}\right)^{2} e^{-\alpha R} \eta_{T} \eta_{R}
$$

Where, transmitter gain, $G_{t}=\left(\pi D_{t} / \lambda\right)^{2}$, receiver gain, $G_{t}=\left(\pi D_{r} / \lambda\right)^{2}[17],[31], D_{t}$ and $D_{r}$ are the geometric diameters of transmitter and receiver, respectively.

Equation (18) can be rewritten as;

$$
P_{R}=\frac{\pi^{2} 10^{10}}{16} \frac{D_{t}^{2} D_{r}^{2}}{\lambda^{2}} \frac{e^{-\alpha R}}{R^{2}} \eta_{T} \eta_{R} P_{t}
$$

II.2.1 Ray trace model [18]

Optical power density transmitted by LED can be expressed as [9], [11], [18], [19];

$$
\mathrm{P}_{\mathrm{t} \text { density }}=\mathrm{P}_{\mathrm{t}} 2(1+\mathrm{m})\{\cos (\theta)\}^{\mathrm{m}} \frac{1}{4 \pi \mathrm{R}^{2}} \eta_{t}
$$

Where, $\mathrm{P}_{t \text { density }}$ is the transmitted optical power, $\mathrm{P}_{\mathrm{t}}$ is the transmitted optical power, $\mathrm{m}$ is the Lambertian mode number of the radiation lobe related to the LED directivity, $\mathrm{R}$ is the distance from the transmitter, $\eta_{t}$ is the efficiency of the transmitter and $\theta$ is the angle between the transmitter beam axis and the line between transmitter and receiver.

The expression $\left\{2(\mathrm{~m}+1) \cos ^{\mathrm{m}}(\theta)\right\}$ can be defined as the transmitter gain $\left(\mathrm{G}_{\mathrm{T}}\right)$

$$
\begin{aligned}
& G_{T}=2(1+m)\{\cos (\theta)\}^{m} \\
\text { Where, } \quad & m=\ln (2) / \ln \left\{\cos \left(\varphi_{1 / 2}\right)\right\}
\end{aligned}
$$

and $\Phi_{1 / 2}$ is the half-power angle of the transmitter

From Eq.21, $\mathrm{G}_{\mathrm{T}}$ independent upon the wavelength and $\mathrm{G}_{\mathrm{T}}$ is a function of $\theta$ and $\varphi_{1 / 2}$

At receiver with Beer's law, the power density $\left(\mathrm{P}_{\mathrm{r} \text { density }}\right)$ is;

$$
P_{\text {r density }}=\frac{P_{t} G_{T}}{4 \pi R^{2}} e^{-\alpha R} \eta_{t}
$$

Where, $\mathrm{e}^{-\mathrm{aR}}$ is the medium (water) losses.

The received optical power

$$
P_{r}=\frac{P_{t} G_{T}}{4 \pi R^{2}} e^{-\alpha R} A_{r \text { eff }} \eta_{t} \eta_{r}
$$

Where, $\eta_{\mathrm{r}}$ is the quantum efficiency of the receiver, $A_{r \text { eff }}\left\{A_{r}\right.$ eff $\left.=A_{r} \cos (\gamma)\right\}, A_{r}$ is the physical receive area, $\gamma$ is the angle between the perpendicular to the receiver plane area and the ray which incident on the receiver area.

Equation (18) can be rewritten as;

$$
P_{R}=\frac{P_{t} G_{t}}{4 \pi R^{2}} \quad e^{-\alpha R} \quad A_{r \text { eff }} \eta_{t} \eta_{R}
$$

The format of Eq.24 is the same format of Eq.25, but, $G_{t}=\left(\pi D_{t} / \lambda\right)^{2}$ instead of $G_{T}=2(m+1) \cos ^{m}(\theta)$

The value of $\mathrm{G}_{\mathrm{T}}$ decreases with higher values of half-power angle $\left(\varphi_{1 / 2}\right)$ and large values of in alignment angle $(\theta)$ as shows in Fig.4. Also Fig.4 indicates that after the specific value of angle $\theta\left(\theta=8^{\circ}\right)$ the gain $\mathrm{G}_{\mathrm{T}}\left(\varphi_{1 / 2}=10^{\circ}\right)>\mathrm{G}_{\mathrm{T}}\left(\varphi_{1 / 2}=5^{\circ}\right)$ and $\mathrm{G}_{\mathrm{T}}\left(\varphi_{1 / 2}=15^{\circ}\right)>\mathrm{G}_{\mathrm{T}}\left(\varphi_{1 / 2}=5^{\circ}\right)$. The parameter $\mathrm{m}$ rapidly decreases with $\varphi_{1 / 2}$ as shown in Fig.5.

Also, Table 1 indicates that $G_{T}$ increases by reducing the value of $\varphi_{1 / 2}\left(\varphi_{1 / 2}\right.$ is reduced by selecting the LED or by using lenses[9]). The increasing factor of $\mathrm{G}_{\mathrm{T}}$ due to reducing $\varphi_{1 / 2}$ is;

$$
\text { increasing factor of } G_{\mathrm{T}} \text { due to reduce } \varphi_{1 / 2},=10 \log \left\{\frac{\mathrm{G}_{\mathrm{T}} \text { at } \varphi_{1 / 2}=5^{0}}{\mathrm{G}_{\mathrm{T}} \text { at } \varphi_{1 / 2}}\right\}
$$

Note 6: From Fig.4 and Table 1, at specific values of angle $\theta$ the increasing factor becomes less one. And so, the $\varphi_{1 / 2}$ must be chosen to optimize with $\theta$

The field of view of the receiver $\left(\mathrm{FOV}_{\mathrm{r}}\right)$ must be greater than the field of view of an $\mathrm{LED}, \mathrm{FOV} \mathrm{TX}_{\mathrm{TX}}=$ $\varphi_{1 / 2}$ [11]. The field of view of a receiver $\left(F O V_{R x}\right)$ is defined as the angle between the points on the detection pattern, where the directivity is reduced to $50 \%$ [11]. 
The maximum incident angle $\theta_{\max }$ to avoid the geometric losses must be less than $\varphi_{1 / 2}$;

$$
\theta_{\max }=\cos ^{-1}\left(\mathrm{~L} / \mathrm{R}_{\max }\right) \quad \text { where, } \mathrm{R}_{\max }=\left\{\left(\mathrm{L}^{2}+\left(\mathrm{D}_{\mathrm{r}} / 2\right)^{2}\right\}^{0.5}\right.
$$

Note 7; some references state that, the received power Eq.20 multiplied by $\operatorname{rect}\left(\mathrm{FOV}_{\mathrm{r}} / \mathrm{FOV}_{\mathrm{r}}\right)$ [9], [18], [19] but by using the ratio of receiving area to the transmitted area and the centroid losses are useful for power losses. Where the value of $\operatorname{rect}\left(\mathrm{FOV}_{\mathrm{r}} / \mathrm{FOV}_{\mathrm{r}}\right)=1$ if $\mathrm{FOV}_{\mathrm{t}}$ less than $\mathrm{FOV}_{\mathrm{r}}$ and $\operatorname{rect}\left(\mathrm{FOV}_{\mathrm{r}} / \mathrm{FOV}_{\mathrm{r}}\right)=0$ if $\mathrm{FOV}_{\mathrm{t}}>\mathrm{FOV}_{\mathrm{r}}[11]$

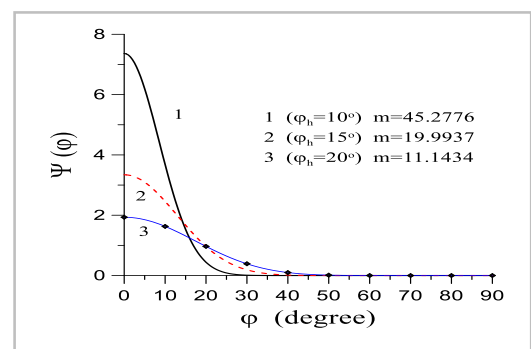

Fig.4 Transmitter gain $\mathrm{G}_{\mathrm{T}}$ versus angle $\theta$ (Eq.21)

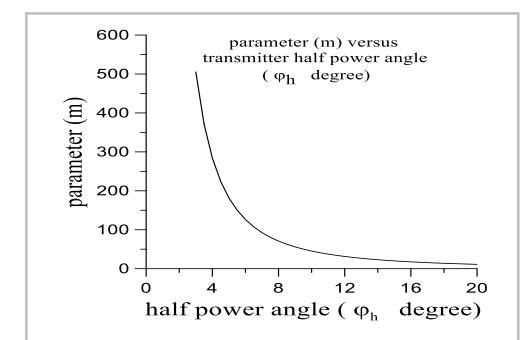

Fig.5 the parameter $\mathrm{m}$ versus $\varphi_{1 / 2}($ Eq.22)

Table 1 Transmitter Gain $\left(\mathrm{G}_{\mathrm{T}}\right)$ due to reduction the transmitter half-power angle

\begin{tabular}{|c|c|c|c|c|c|c|}
\hline \multirow{2}{*}{$\begin{array}{c}\theta \\
\text { degree } \\
0\end{array}$} & \multicolumn{2}{|c|}{$\begin{array}{l}\text { Increasing of } G_{T} \\
\text { du to decrease } \\
\varphi 1 / 2 \text { from } 10^{\circ} \text { to } 5^{\circ}\end{array}$} & \multicolumn{2}{|c|}{ 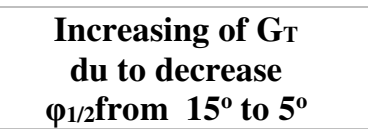 } & \multicolumn{2}{|c|}{$\begin{array}{l}\text { Increasing of } G_{T} \\
\text { du to decrease } \\
\text { (1/2from } 20^{\circ} \text { to } 5^{\circ}\end{array}$} \\
\hline & 3.95 & $5.966 \mathrm{~dB}$ & 8.7096 & $9.4 \mathrm{~dB}$ & 15.0557 & $11.564 \mathrm{~dB}$ \\
\hline 5 & 3.3473 & $3.7056 \mathrm{db}$ & 4.6989 & $6.72 \mathrm{~dB}$ & 9.8542 & $10.671 \mathrm{~dB}$ \\
\hline 10 & 0.4885 & $-3.111 \mathrm{~dB}$ & 0.7311 & $-1.36 \mathrm{~dB}$ & 1.1041 & $1.945 \mathrm{~dB}$ \\
\hline 15 & 0.0348 & $-14.59 \mathrm{db}$ & 0.0319 & $-14.96 \mathrm{~dB}$ & 0.0406 & $-12.748 \mathrm{~dB}$ \\
\hline
\end{tabular}

The dimensions of the received area are around $\mathrm{cm}^{2}$ and so the received power density can be considered equally through the receiver area as shown in Fig.6

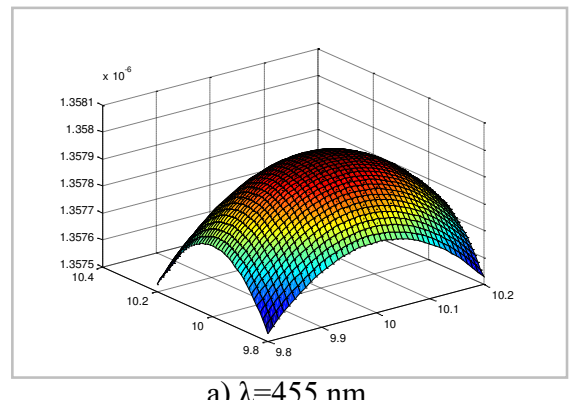

a) $\lambda=455 \mathrm{~nm}$

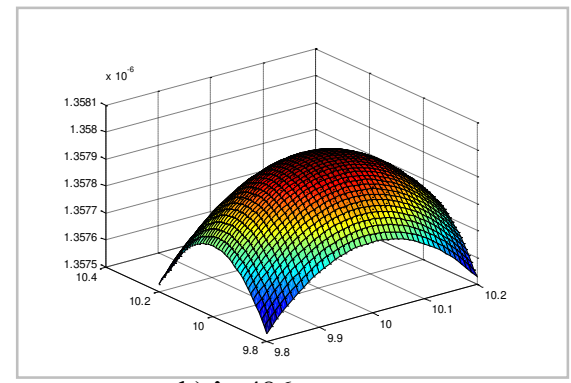

b) $\lambda=486 \mathrm{~nm}$

Fig.6 The received optical power through the received area With $\varphi_{1 / 2}=5^{\circ}, \mathrm{L}=150 \mathrm{~m}, \mathrm{~A}_{\mathrm{r}}=0.04 \mathrm{~m}^{2}$ and $\mathrm{LOS}$

Temperature dependence of the maximum propagation distance $\left(L_{\max }\right)$

The maximum distance $\mathrm{L}_{\max }$ occurs with available minimum received power $\left(\mathrm{P}_{\mathrm{rmin}}\right.$, receiver sensitivity) with the effect of water temperature. From Eq.22 $\mathrm{L}_{\max }$ is;

$$
\begin{aligned}
& L_{\max }^{2} \exp \left(\alpha L_{\max }\right)=\mathrm{F}_{\max } \\
& \text { where, } \quad F_{\max }=\frac{\pi^{2} 10^{10}}{16} \frac{\mathrm{D}_{\mathrm{t}}^{2} \mathrm{D}_{\mathrm{r}}^{2}}{\lambda^{2}} \eta_{\mathrm{t}} \eta_{\mathrm{R}} \frac{\mathrm{P}_{\mathrm{t}}}{\mathrm{P}_{\mathrm{R} \min }} \quad \text { (Independent on temperature) }
\end{aligned}
$$

We noticed that for the same value of $\mathrm{F}$, as $\mathrm{T}$ increases, the corresponding available distance decreases. With distance link $(\mathrm{L}=500 \mathrm{~m})$, parameter $\log (\mathrm{F})$ is the smallest at $\lambda=486 \mathrm{~nm}$ as shown in Fig.7.
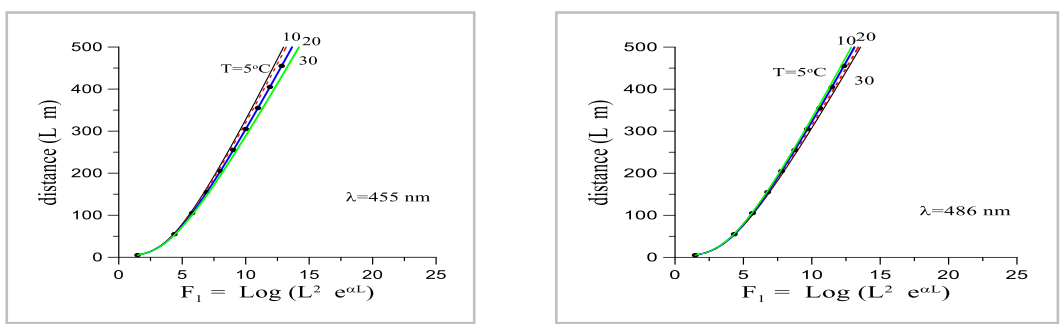

Fig.7 Value of $\mathrm{L}$ versus $\mathrm{F}_{1}$ at different values of $\mathrm{T}$ 
The dependence of distance $\mathrm{L}$ on $\mathrm{T}$ becomes little with $\lambda=455$ and $486 \mathrm{~nm}$ as shown in Fig.7. The required value of the parameter $\log (\mathrm{F})$ to give distance $\mathrm{L}=500 \mathrm{~m}$ is

For $\lambda=455 \mathrm{~nm}, \mathrm{~F}_{1}=12.9833\left(\mathrm{~T}=5^{\circ} \mathrm{C}\right), 13.1910\left(\mathrm{~T}=10^{\circ} \mathrm{C}\right), 13.6587\left(\mathrm{~T}=20^{\circ} \mathrm{C}\right)$ and $14.1958\left(\mathrm{~T}=30^{\circ} \mathrm{C}\right)$

For $\lambda=486 \mathrm{~nm}, \mathrm{~F}_{1}=13.5660\left(\mathrm{~T}=5^{\circ} \mathrm{C}\right), 13.4049\left(\mathrm{~T}=10^{\circ} \mathrm{C}\right), 13.1221\left(\mathrm{~T}=20^{\circ} \mathrm{C}\right)$ and $13.8920\left(\mathrm{~T}=30^{\circ} \mathrm{C}\right)$

As expected, the required value of the parameter $\log (\mathrm{F})$ to give propagation distance $\mathrm{L}=500$ $\mathrm{m}$ increases with $\mathrm{T}$.

\section{II.2.2 Signal to noise ratio (SNR) and bit error rate (BER)}

The most simple and the spread modulation technique is indirect modulation with direct detection (IM/DD) and it is the most common technique for underwater optical communications[1], [11] with On-Off keying with NRZ [1], [2], [17], [32], [33].

The relation between BER and SNR for OOK-NRZ in [18], [34]can be rewritten as;

$$
B E R=10^{-0.21715 S N R} /(2 \pi S N R)^{0.5}
$$

For underwater optical communications BER can be equal to $10^{-6}[35]$ also threshold $B E R=10^{-9}[19]$

From Eq. 25 , with $B E R=10^{-6}$ (the value of $S N R=23$, i.e. $13.6 \mathrm{~dB}$ ) while with $B E R=10^{-9}$ (the value of $\mathrm{SNR}=36$, i.e. $15.56 \mathrm{~dB}$ )

With OOK-NRZ, PIN detector with bandwidth $\Delta \mathrm{F}=\mathrm{B}_{\mathrm{r}} / 2,\left(\mathrm{~B}_{\mathrm{r}}\right.$ is the data rate), the SNR is [35]

$$
S N R=\eta_{r} N_{p}
$$

Where, $\eta_{\mathrm{r}}$ is the quantum receiver efficiency, and $\mathrm{N}_{\mathrm{p}}$ is the number of photons per bit.

The received optical power $\left(\mathrm{P}_{\mathrm{R}}\right)$ also, can be defined as [22], [36]

$$
P_{R}=\eta_{R} N_{p} B_{r} h c / \lambda
$$

Where, $\mathrm{h}$ is the Plank's constant $\left(\mathrm{h}=6.625^{*} 10^{-34}\right.$ joule. Second) and c speed of light in vacuum ( $\mathrm{c}=$ $3 * 10^{8} \mathrm{~m} / \mathrm{s}$ ),

Therefore from Eqs.22 and 27 into Eq.26,

$$
S N R=\frac{\pi^{2} 10^{18}}{16 * 19.875} \frac{\mathrm{D}_{\mathrm{t}}^{2} \mathrm{D}_{\mathrm{r}}^{2}}{\lambda} \frac{\mathrm{e}^{-\alpha \mathrm{R}}}{\mathrm{R}^{2}} \eta_{\mathrm{T}} \eta_{\mathrm{R}} \frac{P_{t} \lambda}{B_{r}}
$$

Where, $\lambda(\mathrm{nm}), \mathrm{B}_{\mathrm{r}}(\mathrm{Gbps}), \mathrm{P}_{\mathrm{t}}(\mathrm{W}), \mathrm{R}(\mathrm{m}), \mathrm{D}_{\mathrm{t}}(\mathrm{cm}), \mathrm{D}_{\mathrm{r}}(\mathrm{cm})$ and $\alpha\left(\mathrm{m}^{-1}\right)$,

Thus, the value of SNR increases with $P_{t}, D_{t}$ and $D_{r}$ while SNR decreases with distance (R), water attenuation factor $\left(\alpha_{\mathrm{FWT}}\right)$, wavelength $(\lambda)$, and data rate $\left(\mathrm{B}_{\mathrm{r}}\right)$

As expected the value of SNR decreases with $\mathrm{T}$ (where, attenuation increases with $\mathrm{T}$ ) with wavelength $455 \mathrm{~nm}$, while SNR increases with temperature with $\lambda=486 \mathrm{~nm}$ as shown in Fig.8. Also, the value of $\mathrm{SNR}>\mathrm{SNR}_{\min }$ for $\lambda=455$ and $487 \mathrm{~nm}$.

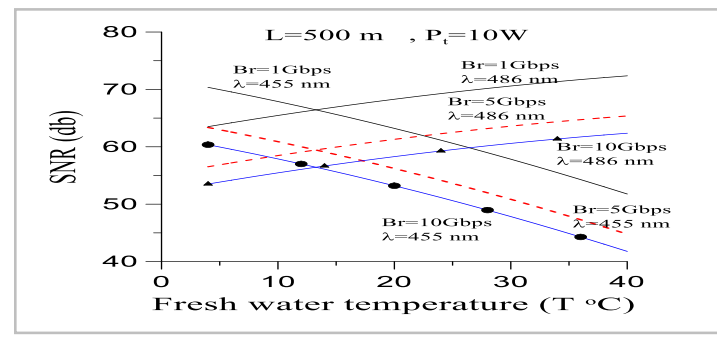

Fig. 8 SNR versus T with $\varphi_{1 / 2}=5^{\circ}$ and $\mathrm{L}=150 \mathrm{~m}, \mathrm{~A}_{\mathrm{r}}=0.04 \mathrm{~m}^{2}$ and $\mathrm{LOS}$

The dimensions of the received area are around tenths of $\mathrm{cm}^{2}$ and so the SNR can be considered equally through the receiver as shown in Fig.9.

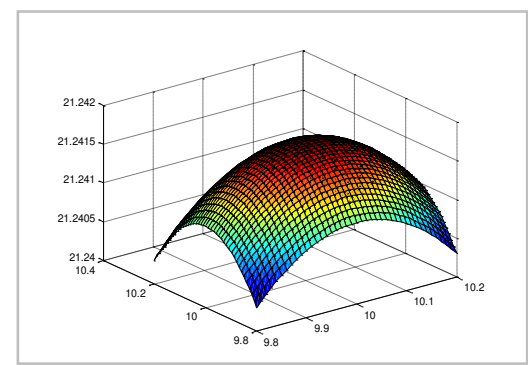

a) $\lambda=455 \mathrm{~nm}$

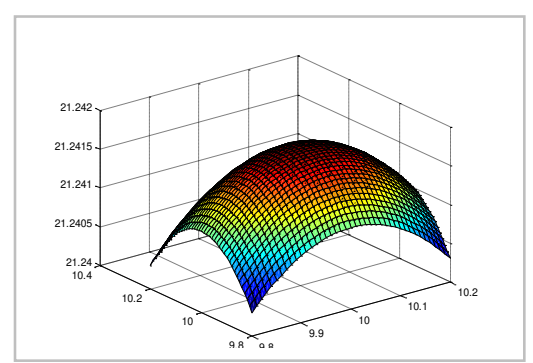

b) $\lambda=487 \mathrm{~nm}$

Fig.9 SNR distribution through the received area with $\varphi_{1 / 2}=5^{\circ}$ and $\mathrm{L}=150 \mathrm{~m}, \mathrm{~A}_{\mathrm{r}}=0.04 \mathrm{~m}^{2}$ and $\operatorname{LOS}$ 
II.2.3 Data rate $\left(\mathbf{B}_{\mathbf{r}}\right)$ [35]

$$
\mathrm{B}_{\mathrm{r}}=\frac{250}{\mathrm{RD}_{\mathrm{m}} \sigma}
$$

Where, $\sigma$ is the source line width $(\mathrm{nm}), \mathrm{D}_{\mathrm{m}}$ material dispersion $(\mathrm{ps} / \mathrm{m} \mathrm{nm}), B_{\mathrm{r}}$ is the data rate $(\mathrm{Gb} / \mathrm{s})$ and $\mathrm{R}$ is the distance $(\mathrm{m})$.

\section{II.3 Availability of link}

The link becomes available with $\mathrm{SNR}>\mathrm{SNR}_{\min }$ and $\mathrm{P}_{\mathrm{r}}>\mathrm{P}_{\mathrm{rmin}}$ where, $\mathrm{P}_{\mathrm{r} \text { min }}$ is the minimum required received power (receiver sensitivity) and $S_{N R}$ min is the lowest $S N R$ with the required BER.

(as example, Sensitivity $=-43 \mathrm{dm}=50 \mathrm{nW}[18]$ )

For minimum received power $\left(\mathrm{P}_{\mathrm{r} \text { min }}\right)$, the required transmitted power from Eq.27 is ;

$P_{\text {t req Prmin }}=\frac{16 * 10^{-10}}{\pi^{2}} \frac{\lambda^{2}}{D_{t}^{2} D_{r}^{2}} \quad R^{2} e^{\alpha R} \frac{1}{\eta_{T} \eta_{R}} \quad P_{R m i n}$

For required SMR (SNRreq), the required transmitted power from Eq.29 is ;

$P_{\text {treq SNR }}=\frac{16 * 19.875 * 10^{-18}}{\pi^{2}} \frac{\lambda}{\mathrm{D}_{\mathrm{t}}^{2} \mathrm{D}_{\mathrm{r}}^{2}} \quad \mathrm{R}^{2} \mathrm{e}^{\alpha \mathrm{R}} \frac{B_{r}}{\eta_{\mathrm{T}} \eta_{\mathrm{R}}} S N R_{\text {req }}$

Therefore the final required transmitted power $P_{t \text { req }}$ is the smaller value of $\left(P_{t \text { req Prmin }}, P_{t \text { req SNR req }}\right)$

III Simulation Proposed design optical link under fresh water (Egypt Nile river water); Table 2 data of the simulation Design example

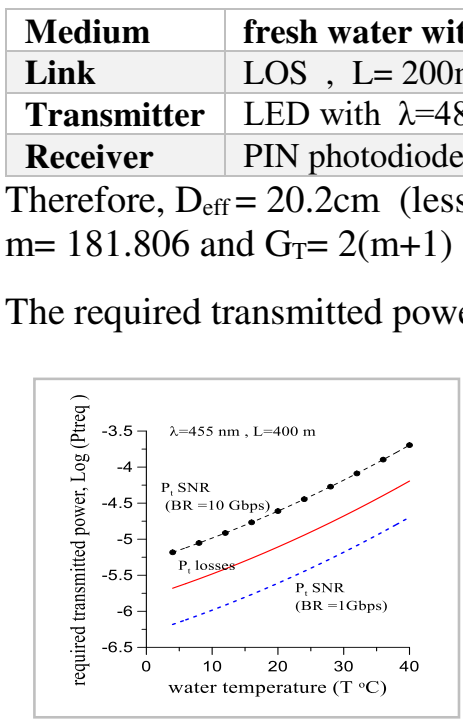

a) $\mathrm{L}=400 \mathrm{~m}$

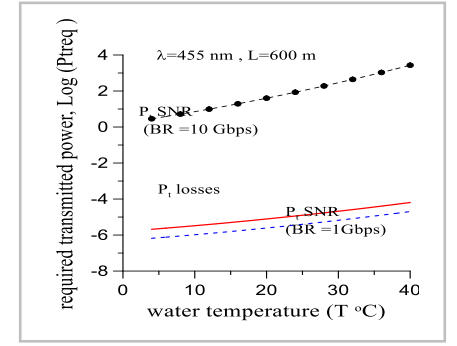

b) $\mathrm{L}=600 \mathrm{~m}$

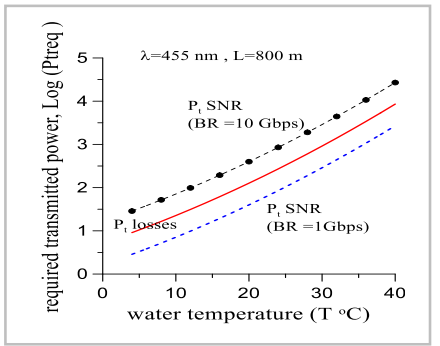

c) $\mathrm{L}=800 \mathrm{~m}$

Fig.10 Required transmitted power $\left(\mathrm{P}_{\mathrm{t} \text { req }} \mathrm{Watt}\right)$ versus temperature $(\mathrm{T})$

With data of simulation proposed design example (with $\lambda=455 \mathrm{~nm}),\left(\mathrm{P}_{\mathrm{rmin}}=-43 \mathrm{dm}\right.$ and $\left.\mathrm{SNR}_{\min }=15.56 \mathrm{db}\right)$

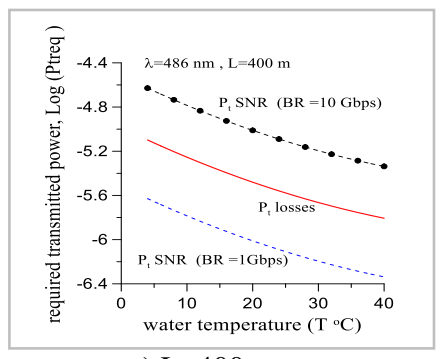

a) $\mathrm{L}=400 \mathrm{~m}$

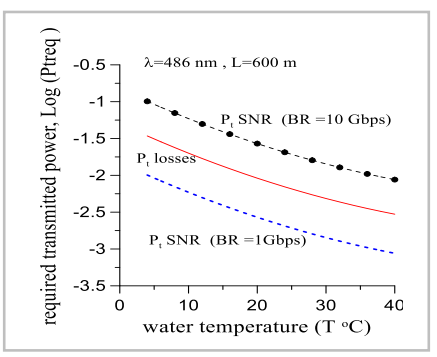

b) $\mathrm{L}=600 \mathrm{~m}$

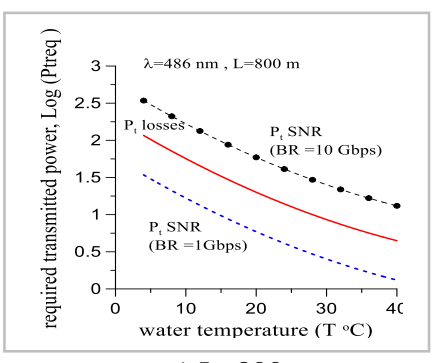

c) $\mathrm{L}=800 \mathrm{~m}$

Fig.11 Required transmitted power $\left(\mathrm{P}_{\mathrm{t} \text { req }} \mathrm{Watt}\right)$ versus temperature $(\mathrm{T})$

With data of simulation proposed design example (with $\lambda=486 \mathrm{~nm}),\left(\mathrm{P}_{\mathrm{rmin}}=-43 \mathrm{dm}\right.$ and $\mathrm{SNR}_{\min }=15.56 \mathrm{db}$ )

\section{Conclusion}

The underwater visible optical communications are affected by the water temperature. As the water temperature increases, the link distance decreases with $\lambda=455 \mathrm{~nm}$ but it increases with $\lambda=455 \mathrm{~nm}$. So the link availability depends upon the daily and seasonal temperature. With 
freshwater (Egypt Nile River water), the best wavelength is $\lambda=486 \mathrm{~nm}$. To overcome the unavailability of the link due to the water temperature, the transmitted power must be controlled by the daily water temperature. As the data rate increases, the link distance decreases. With wavelength $\lambda=486 \mathrm{~nm}$, the link can be greater than $500 \mathrm{~m}$ with a data rate $=1 \mathrm{Gbps}$.

\section{References}

[1] L. K. Gkoura et al., "Underwater Optical Wireless Communication Systems: A Concise Review," in Turbulence Modelling Approaches - Current State, Development Prospects, Applications, 2017, pp. 219-236.

[2] N. Saeed, A. Celik, T. Y. Al-Naffouri, and M. S. Alouini, "Underwater optical wireless communications, networking, and localization: A survey," Ad Hoc Networks, pp. 1-40, 2019, doi: 10.1016/j.adhoc.2019.101935.

[3] G. Schirripa Spagnolo, L. Cozzella, and F. Leccese, "Underwater Optical Wireless Communications: Overview,” Sensors, vol. 20, no. 8, pp. 1-14, Apr. 2020, doi: 10.3390/s20082261.

[4] L. Mathew, Y. P. Singh, and S. Sharma, "An Extensive Study on Under-water Communication using LED / LASER Enabled Li-Fi Modules," An Extensive Study Under-water Commun. using LED / LASER Enabled Li-Fi Modul., vol. 5, no. 11, pp. 19435-19440, 2016, doi: 10.15680/IJIRSET.2016.0511129.

[5] M. E. S.Vanathi, M.E(CSE)*V.MALA, "LED Lamp Based Visible Light Communication in Underwater Vehicles,” Int. J. Eng. Trends Technol., vol. 4, no. 2, pp. 3385-3391, 2018, doi: 10.14445/22315381/ijett-v13p222.

[6] D. Kiran Xalxo and V. Muralidharan, "Subaquatic Message Transmission Using Lifi,” Int. J. Trendy Res. Eng. Technol., vol. 2, no. 2, pp. 22-25, 2018, [Online]. Available: http://trendytechjournals.com/April issue 26.pdf.

[7] C. Mahendran, K. N. Kumar, and V. Jeyamohan, "Underwater Wireless Communication Using Visible Light LEDs," Int. J. Innov. Res. Sci. Eng. Technol. IJIRSET, vol. 8, no. 2, pp. 1174-1179, 2019.

[8] I. S. Reddy, A. U. V, and M. P. Anup, "Underwater Wireless Communication System For Large Distance Transmission," vol. 10, no. 5, pp. 943-948, 2017.

[9] C. Wang, H. Y. Yu, and Y. J. Zhu, "A long distance underwater visible light communication system with single photon avalanche diode," IEEE Photonics J., vol. 8, no. 5, pp. 1-12, 2016, doi: 10.1109/JPHOT.2016.2602330.

[10] G. P. Raj and P. Prabakaran, "Underwater Communication through Light Waves," Int. J. Trends Eng. Technol., vol. 23, no. 1, pp. 17-21, 2017.

[11] S. Dimitrov and H. Haas, Principles of LED light communications: Towards networked Li-Fi. 2015.

[12] P. M. Moser, "Spectral transmission of light through sea water," Nav. Air Dev. Cent. Warm. -Pacific Sierra Res. Corp., no. September, pp. 1-16, 1992, [Online]. Available: http://www.dtic.mil/docs/citations/AD1012965.

[13] C. D. Mobley, "The optical properties of water," Handb. Opt., vol. Second Edi, pp. 60-144, 1995.

[14] F. Abdalkarim Tahir, "Open ocean underwater wireless optical communication: chlorophyll and depth dependent variation in attenuation." Universiti Tun Hussein Onn Malaysia, 2015.

[15] H. M. Oubei et al., "Light based underwater wireless communications," Jpn. J. Appl. Phys., vol. 57, no. 5, pp. 1-52, Aug. 2018, doi: 10.7567/JJAP.57.08PA06.

[16] Z. Ghassemlooy, W. Popoola, and S. Rajbhandari, Optical wireless communications: System and channel modelling with MATLAB®. 2017.

[17] H. Henniger and O. Wilfert, "An introduction to free-space optical communications," Radioengineering, vol. 19, no. 2, pp. 203-212, 2010.

[18] A. F. Hussein, A. A. El Aziz, H. A. Fayed, and M. A. Aly, "A free space optical link in a laboratory environment," in 2015 IEEE Student Conference on Research and Development, SCOReD 2015, 2015, pp. 317-321, doi: 10.1109/SCORED.2015.7449344.

[19] F. Miramirkhani and M. Uysal, "Visible light communication channel modeling for underwater environments with blocking and shadowing," IEEE Access, vol. 6, pp. 1082-1090, 2017.

[20] Balaji K et al., "Modelling of Submerged Optical Remote Correspondences with Low Losses," Int. J. Mech. Prod. Eng. Res. Dev., vol. 10, no. 3, pp. 3983-3998, 2020, doi: 10.24247/ijmperdjun2020378.

[21] R. Röttgers, R. Doerffer, D. McKee, and W. Schönfeld, "Pure water spectral absorption, scattering, and real part of refractive index model Algorithm Technical Basis Document," Univ. Strat. Glas., no. 1, pp. $1-18,2010$.

[22] M.K. Ghosh, Optoelectronics Sensors and Instrumentation. ED-TECH, 2014.

[23] R. M. Pope and E. S. Fry, "Absorption spectrum (380-700 nm) of pure water II Integrating cavity measurements,” Appl. Opt., vol. 36, no. 33, pp. 8710-8723, 1997, doi: 10.1364/ao.36.008710. 
[24] Z. Lu, "Optical absorption of pure water in the blue and ultraviolet.” Texas A\&M University, pp. 78-81, 2007.

[25] A. Morel et al., "Optical properties of the 'clearest' natural waters," Limnol. Oceanogr., pp. 217-229, 2007, doi: 10.4319/lo.2007.52.1.0217.

[26] K. Balaji and S. Shakthivel Murugan, "Implementing IoT in underwater communication using Li-Fi," Int. J. Recent Technol. Eng., vol. 8, no. 2 Special Issue 4, pp. 958-964, 2019, doi: 10.35940/ijrte.B1190.0782S419.

[27] A. N. Z. Rashed and H. A. Sharshar, "Performance evaluation of short range underwater opticalwireless communications for different ocean water types," Wirel. Pers. Commun., pp. 693-708, 2013, doi: 10.1007/s11277-013-1037-8.

[28] X. Zhang, L. Hu, and M.-X. He, "Scattering by pure seawater: Effect of salinity," Opt. Express, vol. 17, no. 7 , p. 5698, Mar. 2009, doi: 10.1364/OE.17.005698.

[29] C. Periasamy, K. Vimal, and D. Surender, "LED Lamp Based Visible Light Communication in Underwater Vehicles," Int. J. Eng. Trends Technol., vol. 13, no. 3, pp. 103-106, Jul. 2014, doi: 10.14445/22315381/IJETT-V13P222.

[30] L. J. Johnson, F. Jasman, R. J. Green, and M. S. Leeson, "Recent advances in underwater optical wireless communications," Underw. Technol. Int. J. Soc. Underw., vol. 32, no. 3, pp. 167-175, Nov. 2014, doi: 10.3723/ut.32.167.

[31] A. Akbulut, H. A. Ilgin, and M. Efe, “Adaptive bit rate video streaming through an RF/Free space optical laser link,” Radioengineering, vol. 19, no. 2, pp. 271-277, 2010.

[32] E. Leitgeb et al., "Analysis and evaluation of optimum wavelengths for free-space optical transceivers," in 2010 12th International Conference on Transparent Optical Networks, Jun. 2010, pp. 1-7, doi: 10.1109/ICTON.2010.5549009.

[33] M. L. Plett et al., "Free-space optical communication link across," Opt. Eng., vol. 47, no. 4, pp. 13-15, 2008.

[34] Y. Dong and M. Sadegh Aminian, "Routing in Terrestrial Free Space Optical Ad-Hoc Networks," Dep. Sci. Technol. Institutionen för Tek. och naturvetenskap Linköping Univ., pp. 23-28, 2014.

[35] G. P. Agrawal, Fiber-optic communication systems, vol. 222. John Wiley \& Sons, 2012.

[36] G. Keiser, "Basic Concepts of Communication Systems," in Optical Communications Essentials, 2004.

\section{Appendix A constants of the above equations}

A.1.1 The values of constants of Eq.1 (a0-a5, k1-k4) for refractive index(nFw) and dispersion (DFw) $\mathrm{a}_{0}=1.31405, \mathrm{a}_{1}-2.02 . * 10^{-6}, \mathrm{a}_{2}=15.868, \mathrm{a}_{3}=-0.00423, \mathrm{a}_{4}=-4382, \mathrm{a}_{5}=1.1455 . * 10^{6}$, $\mathrm{k}_{1}=2433.5 \quad, \mathrm{k}_{2}=0.1659 \quad, \mathrm{k}_{4}=2927.3 \quad, \mathrm{k}_{4}=0.6882$

A.1.2 The values of constants of Eq.3 (values of $d_{0}-d_{16}$ ) for absorption (arw) $\mathrm{d}_{5}=2946754.06375794, \mathrm{~d}_{6}=-42938.4685079806, \mathrm{~d}_{7}=+268.064470562573, \mathrm{~d}_{8}=-0.929447676162257$, $\mathrm{d}_{9}=+0.00193297392952107, \mathrm{~d}_{10}=-2.41124303124049 * 10^{-6}, \mathrm{~d}_{11}=+1.67049307970413 * 10^{-9}$, $\mathrm{d}_{12}=-4.95828243058592 * 10^{-13}$,

A.1.3 The values of constants of Eq.6 (values of d17- d20) for absorption coefficient (aFw) $\mathrm{d}_{17}=-33.46020513, \mathrm{~d}_{18}=+0.2148855903, \mathrm{~d}_{19}=-0.0004364585415, \mathrm{~d}_{20}=+2.864542865^{*} 10^{-7}$

A1.4 The values of constants of Eq.10 (values of $c_{0}$ - $c_{11}$ ) for scattering due to density fluctuations $\left(B_{d}\right)$ $\mathrm{c}_{0}=19652.21, \mathrm{c}_{1}=148.4206, \mathrm{c}_{2}=-2.327105, \mathrm{c}_{3}=1.350477 * 10^{-2}, \mathrm{c} 4=-5.155288 . * 10^{-5}$,

Table A.1: Parameters of Eq.15 (values of $\mathrm{q}_{1}-\mathrm{q}_{5}$ ) fro $\mathrm{n}_{\mathrm{FW}}$ and dispersion $\mathrm{D}_{\mathrm{FW}}$

\begin{tabular}{|l|c|c|c|c|c|c|c|c|c|}
\hline $\boldsymbol{\lambda}$ & $\mathbf{q} 1$ & $\mathbf{q} 2 * \mathbf{1 0}^{-\mathbf{6}}$ & $\mathbf{\mathbf { q } ^ { * } \mathbf { 1 0 } ^ { - \mathbf { 6 } }}$ & $\begin{array}{c}\text { Residual } \\
\mathbf{S} * \mathbf{1 0}^{-15}\end{array}$ & $\begin{array}{c}\text { Error \% } \\
* \mathbf{1 0}^{-\mathbf{6}}\end{array}$ & $\mathbf{q}$ & $\mathbf{q}$ & Residuals & Error \% \\
\hline $\mathbf{4 5 5}$ & 1.3400 & 9.2972 & 2.0201 & 1.99 & 0.000069 & 0.6497 & 0.00013622 & $3.4^{*} 10^{-12}$ & 0.00020 \\
\hline $\mathbf{4 8 7}$ & 1.3382 & 8.7042 & 2.0201 & 1.35 & 0.00011 & 0.50186 & 0.00011891 & $2.8^{*} 10^{-12}$ & 0.00071 \\
\hline
\end{tabular}

Table A.2: Parameters of Eq.16 (values of $\mathrm{q}_{6}, \mathrm{q}_{7}$, and $\mathrm{q}_{8}$ ) for attenuation coefficient $\alpha_{\mathrm{FW}}$ with $\mathrm{C}_{\mathrm{c}}=0 \mathrm{mg} / \mathrm{m}^{3}$

\begin{tabular}{|l|l|l|l|l|l|}
\hline $\boldsymbol{\lambda}$ & \multicolumn{1}{|c|}{$\mathbf{q 6}$} & \multicolumn{1}{|c}{$\mathbf{q}_{\mathbf{7}}$} & \multicolumn{1}{|c|}{$\mathbf{q 8}^{*} \mathbf{1 0}^{-\mathbf{6}}$} & \multicolumn{1}{c|}{ Eesiduals $* \mathbf{1 0}^{-\mathbf{5}}$} & Error \% \\
\hline $\mathbf{4 5 5}$ & 0.0056344 & 0.0015885 & 1.5902 & 9.8 & $0.304-0.043$ \\
\hline $\mathbf{4 8 7}$ & 0.015532 & 0.00097838 & 1.2035 & 7.43 & $0.1545-0.0428$ \\
\hline
\end{tabular}

Table A.3: Parameters of Eq.16 (values of $\mathrm{q}_{6}, \mathrm{q}_{7}$, and $\mathrm{q}_{8}$ ) for attenuation coefficient $\alpha_{\mathrm{FW}}$ with $\mathrm{C}_{\mathrm{c}}=0.005 \mathrm{mg} / \mathrm{m}^{3}$

\begin{tabular}{|l|l|l|l|l|l|}
\hline $\boldsymbol{\lambda}$ & \multicolumn{1}{|c|}{$\mathbf{q 6}$} & \multicolumn{1}{|c|}{$\mathbf{q 7}$} & $\mathbf{q 8}^{*} \mathbf{1 0}^{-\mathbf{6}}$ & \multicolumn{1}{c|}{ Residuals $^{*} \mathbf{1 0}^{-\mathbf{5}}$} & \multicolumn{1}{c|}{ Error \% } \\
\hline $\mathbf{4 5 5}$ & 0.0056364 & 0.0018593 & 1.5902 & 9.8 & $0.224-0.041$ \\
\hline $\mathbf{4 8 7}$ & 0.01811 & 0.0019876 & 1.2035 & 7.4 & $0.135-0.037$ \\
\hline
\end{tabular}

Appendix B Modified Beers law and the effect of $\varphi_{1 / 2}$ on the water losses Losses factor at $\lambda=532 \mathrm{~nm}$ is [21] with pure water $\left(\mathrm{C}_{\mathrm{c}}=0.005 \mathrm{mg} / \mathrm{m}^{3}\right)$ and with clean water $\left(\mathrm{C}_{\mathrm{c}}=0.31 \mathrm{mg} / \mathrm{m}^{3}\right)$ With $\varphi_{1 / 2}=5^{\circ}$ Losses pure water $=0.1999999 \exp (-0.0657156 \mathrm{z})+0.0046431 \exp (-0.2633946 \mathrm{z})$ 
With $\varphi_{1 / 2}=10^{\circ}$ Losses pure water $=0.0859942 \exp (-0.0702351 \mathrm{z})+0.0112750 \exp (-0.2998076 \mathrm{z})$

From Fig.B.1, with distance $\mathrm{z}=10$ to $500 \mathrm{~m}$ and by using fitting curve technique, the approximate above propagation losses factors become;

With $\varphi_{1 / 2}=5^{\circ}$ Losses pure water $\approx \exp (-1.6091-0.0657017 \mathrm{z}) \quad$ with error $=0.13-0.0015 \%$

With $\varphi_{1 / 2}=10^{\circ}$ Losses pure water $\approx \exp (-1.6091-0.0657017 \mathrm{z})$ with error $=0.13-0.0015 \%$

With $\varphi_{1 / 2}=5^{\circ}$ Losses clean water $\approx \exp (-2.2984-0.150817 \mathrm{z}) \quad$ with error $=0.22-0.038 \%$

With $\varphi_{1 / 2}=10^{\circ}$ Losses clean water $\approx \exp (-2.2984-0.150817 \mathrm{z}) \quad$ with error $=1.23-0.001 \%$

So, for pure water $\left(\mathrm{Cc}=0.005 \mathrm{mg} / \mathrm{m}^{3}\right)$, losses with $\varphi_{1 / 2}=5^{\circ}$ (Eq.B.1.5) $=$ losses with $\varphi_{1 / 2}=10^{\circ}$ (Eq.B.6) Also, for clean water $\left(\mathrm{Cc}=0.31 \mathrm{mg} / \mathrm{m}^{3}\right)$, losses with $\varphi_{1 / 2}=5^{\circ}$ (Eq.B.1.7) $=$ losses with $\varphi_{1 / 2}=10^{\circ}($ Eq.B.8)
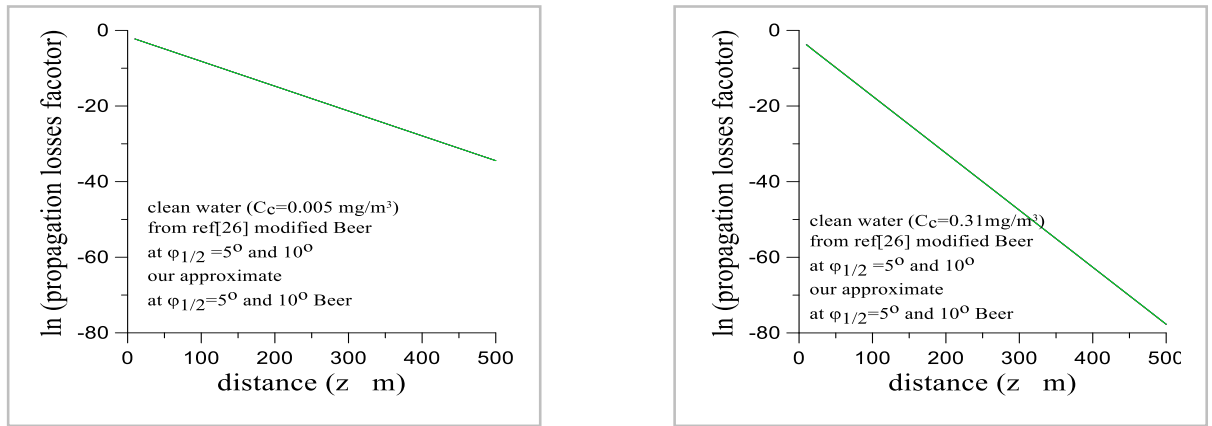

Fig.B.1 Propagation losses factor for pure water and clean water By Beer's law and modified Beer's law at $\lambda=532 \mathrm{~nm}$ 